\title{
Resurrecting an extinct species: archival DNA, taxonomy, and conservation of the Vegas Valley leopard frog
}

\author{
Evon R. Hekkala $\cdot$ Raymond A. Saumure $\cdot$ Jef R. Jaeger • \\ Hans-Werner Herrmann • Michael J. Sredl • David F. Bradford • \\ Danielle Drabeck • Michael J. Blum
}

Received: 2 November 2010/ Accepted: 9 May 2011/Published online: 28 May 2011

(c) The Author(s) 2011. This article is published with open access at Springerlink.com

\begin{abstract}
Suggestions that the extinct Vegas Valley leopard frog (Rana fisheri $=$ Lithobates fisheri) may have been synonymous with one of several declining species have complicated recovery planning for imperiled leopard frogs in southwestern United States. To address this concern, we reconstructed the phylogenetic position of $R$. fisheri from mitochondrial and nuclear sequence data obtained from century-old museum specimens. Analyses incorporating representative North American Rana species placed archival specimens within the clade comprising federally Threatened Chiricahua leopard frogs (Rana chiricahuensis $=$ Lithobates $\quad$ chiricahuensis). Further analysis of Chiricahua leopard frogs recovered two diagnosable lineages. One lineage is composed of $R$. fisheri specimens and $R$. chiricahuensis near the Mogollon Rim in central Arizona, while the other encompasses R. chiricahuensis populations to the south and east. These findings
\end{abstract}

Electronic supplementary material The online version of this article (doi:10.1007/s10592-011-0229-6) contains supplementary material, which is available to authorized users.

E. R. Hekkala · D. Drabeck · M. J. Blum

Department of Ecology and Evolutionary Biology,

Tulane University, New Orleans, LA 70118, USA

R. A. Saumure

Research Division, Las Vegas Springs Preserve, Las Vegas, NV 89107, USA

J. R. Jaeger

School of Life Sciences and Public Lands Institute, University of Nevada, Las Vegas, NV 89154-4004, USA

H.-W. Herrmann

School of Natural Resources and Environment and Arizona

Cooperative Fish and Wildlife Research Unit (USGS),

University of Arizona, Tucson, AZ 85721, USA ascribe $R$. chiricahuensis populations from the northwestern most portion of its range to a resurrected $R$. fisheri, demonstrating how phylogenetic placement of archival specimens can inform recovery and conservation plans, especially those that call for translocation, re-introduction, or population augmentation of imperiled species.

Keywords Archival DNA - Museum specimens - Rana fisheri - Rana chiricahuensis · Taxonomy · Conservation genetics

\section{Introduction}

Conservation of imperiled species requires correct diagnosis of taxonomic status for effective implementation of management actions. The need for reliable taxonomy is most obvious in management plans that involve translocation, re-introduction, population augmentation, or captive propagation (Kleiman 1989). The declining leopard

H.-W. Herrmann

Human Origins Genotyping Laboratory, Arizona Research

Laboratories of Arizona, Tucson, AZ 85721, USA

M. J. Sredl

Arizona Game and Fish Department, Nongame Branch, Phoenix, AZ 85086, USA

D. F. Bradford

US Environmental Protection Agency, National Exposure

Research Lab, Las Vegas, NV 89193-3478, USA

E. R. Hekkala $(\square)$

Fordham University, New York 10458, USA

e-mail: ehekkala@fordham.edu 
frog species (family Ranidae) from southwestern North America present an example of how uncertain taxonomic status can impede or complicate conservation strategies (e.g. Jaeger et al. 2001; Goldberg et al. 2004).

Addressing taxonomic concerns has, until recently, been 'too little, too late' for the extinct Vegas Valley leopard frog (Rana fisheri Stejneger $1893=$ Lithobates fisheri) (Jennings and Hayes 1994). The species was known only from southern Nevada at four localities in the Las Vegas Valley, with individuals last collected in 1942 (Stebbins 1951). Introduced species (particularly bullfrogs, Rana catesbiana [=Lithobates catesbeianus]) and the loss of spring-fed habitats likely contributed to R. fisheri's demise (Wright and Wright 1949; Stebbins 1951). Plans to recover leopard frog populations within Las Vegas Valley have been complicated by suggestions that, based upon morphological similarities (Jennings 1988; Hillis and Wilcox 2005), $R$. fisheri may have been synonymous with either: (1) the relict leopard frog ( $R$. onca [=Lithobates onca]; Jaeger et al. 2001) known from sites in close proximity to the Las Vegas Valley; or (2) the Chiricahua leopard frog (R. chiricahuensis Platz and Mecham $1979=$ Lithobates chiricahuensis), which has its closest populations $400 \mathrm{~km}$ distant along the Mogollon Rim of central Arizona (Platz and Mecham 1979).

Both $R$. onca and $R$. chiricahuensis have experienced dramatic population declines and range contractions (Bradford et al. 2004; Sredl and Jennings 2005). Rana chiricahuensis is now listed as federally Threatened under the US Endangered Species Act and R. onca is managed under a voluntary conservation agreement. Management plans for both species rely on expansion or re-establishment of populations. Accordingly, both species may be candidates for establishment in the Las Vegas Valley. The uncertain taxonomic status of extinct $R$. fisheri, however, raises questions about whether such an action would represent a translocation of an imperiled species to nearby vacant habitat or a re-introduction of a threatened species into former habitat. Herein, we present the first genetic analysis of $R$. fisheri from century-old archival museum specimens to address alternative taxonomic hypotheses, and in so doing, to advance the recovery planning of imperiled leopard frogs across southwestern North America.

\section{Materials and methods}

Archival samples

Tissues were sampled from 33 historic $R$. fisheri specimens housed at the California Academy of Sciences (Supplementary
Table 1). Of these samples, collections made in 1913 (Van Denburgh and Slevin 1921) were preserved in ethanol while those from 1938 were preserved in formalin. During tissuing, surgical utensils and work areas were wiped with DNA away (Molecular Bioproducts) between samples.

DNA from $R$. fisheri tissue samples was extracted using a DNeasy tissue kit (Qiagen) according to the manufacturer's instructions with the following modifications: tissue samples were first soaked for $36 \mathrm{~h}$ with three changes of PBS at $12 \mathrm{~h}$ intervals. During tissue digestion, $5 \mu \mathrm{l}$ of dithiothreitol was added along with proteinase $\mathrm{K}$ to enhance protein digestion. DNA was initially selectively bound to the DNeasy membrane and then eluted from the membrane using manufacturer provided buffer heated to $56^{\circ} \mathrm{C}$ and left to sit in the column for 20 min prior to centrifugation. All elutions were performed twice with $80 \mu \mathrm{l}$ of buffer provided with the kit. Extractions from contemporary samples (collected 1980-2009) were carried out as per manufacturer recommendations in separate facilities.

All processing (extraction and amplification) of archival samples from 1910 to 1939 took place in a separate, clean facility with protocols recommended for use with degraded or ancient DNA (Gilbert et al. 2005). All pre- and post PCR handling was also separated, and positive and negative controls were used during PCR setup. Archival tissue samples were re-extracted, amplified and sequenced in triplicate for verification. Only those samples with triplicate confirmation of sequence data were used in the analyses.

\section{Contemporary samples}

In order to explore the phylogenetic affinity of the archival $R$. fisheri specimens, we needed to provide a comparative sequence library for representative southwestern and western ranid frog species. We used a combination of Genbank accessioned sequences (Dataset I (GI55418335-GI55418396) from Hillis and Wilcox 2005, Supplementary Table 2a) and sequences generated from ranid tissue samples collected during recent surveys (>1980) (Supplementary Table 2c).

Unpublished data for a large set of $R$. chiricahuensis samples collected as part of a separate project, were made available for our use (Data set III, $n=229$, Supplementary Table 2c). These samples were processed, including extraction and data generation, entirely at University of Arizona, Tucson. For the current project a subsample of DNA templates from that collection (Dataset II, $n=26$, Supplementary Table 2 b) were used to generate data for additional gene regions at Tulane University. These samples were processed after completion of the archival specimen data collection. 
Table 1 Primers and sample sizes of historical Rana fisheri specimens (Supplementary Table 1) and congeners by gene region

\begin{tabular}{|c|c|c|c|c|c|c|}
\hline Gene region & Primer $5^{\prime}-3^{\prime}$ sequence & $\begin{array}{l}\mathrm{n} \\
R f\end{array}$ & $R c$ & Ro & $R p$ & $\begin{array}{l}\text { Total basepairs } \\
1191\end{array}$ \\
\hline Control region & & 11 & 26 & 1 & 1 & 281 \\
\hline RfcrF1 & 5'-ATTAAGTACCCCATATTATGCTTTCT-3' & & & & & \\
\hline RfcrF2 & 5'-TGGTTTAATTTATATACATATT-3' & & & & & \\
\hline RfcrF3 & 5'-TGTATTAATCTATTTATGTCT-3' & & & & & \\
\hline RfcrR1 & 5'-TATACATGTAAGTACTAATGC-3' & & & & & \\
\hline Rhodopsin exon & & 7 & 20 & 1 & NA & 278 \\
\hline RhodF & 5'-TCAGTATTACCTGGCAGAGCCATGG-3' & & & & & \\
\hline Rhod1A & 5'-ACCATGAACGGAACAGAAGGYCC-3' & & & & & \\
\hline Rhod1C & 5'-CCAAGGGTAGCGAAGAARCCTTC-3' & & & & & \\
\hline Rhod1D & 5'-GTAGCGGAAGAARCCTTCAAMGTA-3' & & & & & \\
\hline $12 \mathrm{~s}$ & & 15 & 23 & 1 & 2 & 632 \\
\hline Ro12 s216F & 5'-CAAYACGTCAGGTCAAGGTG-3' & & & & & \\
\hline Ro12 s460R & 5'-CYTGTTTCGACTTGCCTCTT-3' & & & & & \\
\hline
\end{tabular}

Rf-Rana fisheri, Rc-Rana chiricahuensis, Ro—Rana onca, Rp-Rana pipiens

Markers and sequencing

Oligonucleotide primers were designed from published $R$. onca, R. chiricahuensis and $R$. pipiens sequences to amplify short (ca. $200 \mathrm{bp}$ ) fragments of mitochondrial (mtDNA) $12 \mathrm{~s}$, Control Region (CR), and the nuclear Rhodopsin exon 1 region (Table 1). Primers incorporated base ambiguities to increase possible amplification of the anonymous $R$. fisheri DNA. All amplifications were performed on either a Perkins-Elmer or MJ Research thermocycler in 20-25 ml volumes. Cocktails included a PCR "Illustra puretaq READY-TO-GO" bead (GE Healthcare), 2-4 nmole template DNA; $2 \mu \mathrm{M}$ mixed forward and reverse primer, with $\mathrm{ddH}_{2} \mathrm{O}$ to volume. PCR parameters included initial denaturing of $4 \mathrm{~min}$ at $94^{\circ} \mathrm{C}$, followed by a $7 \mathrm{~min}$ extension with 31 subsequent cycles of $1 \mathrm{~min}$ at $94^{\circ} \mathrm{C}, 1 \mathrm{~min}$ at $48-59^{\circ} \mathrm{C}$ and $1.5 \mathrm{~min}$ at $72^{\circ} \mathrm{C}$, followed by a final $4 \mathrm{~min}$ extension at $72^{\circ} \mathrm{C}$. Amplicons were purified using ExoSAPIt (USB). Forward and reverse cycle sequencing reactions were performed using BigDye chemistry, and analyzed on an ABI3100 automated sequencer (Applied Biosystems). Raw sequence files were edited, assembled, and aligned with Sequencher 4.9 (Gene Codes). Individual marker datasets were compiled and aligned individually in MEGA4 (Tamura et al. 2007) utilizing Clustal W (Larkin et al. 2007) $($ Gap penalties $=50$, Gap Extension penalties $=25)$ and checked by eye prior to concatenation.

\section{Analyses}

We used an iterative approach to assess the taxonomic affinity of $R$. fisheri. Using MRBAYES, v.3.0b3 (Huelsenbeck and Ronquist 2001), we performed phylogenetic analyses of two datasets comprised of: (I) 12 s for $R$. fisheri and North American Ranidae Genbank sequences (Hillis and Wilcox 2005, Supplementary Table 2a); and (II) combined short, mtDNA (Control region and $12 \mathrm{~s}$ ) and nuclear (Rhodopsin exon 1) regions for $R$. fisheri, $R$. chiricahuensis from a broad geographic distribution, and Genbank sequences of other representative southwestern ranid species (Hillis and Wilcox 2005; Frost et al. 2006; Supplementary Table 2b). Each marker for Dataset II was initially analyzed independently with the substitution model specified by MR. MODELTEST v.2.3 (Posada and Crandall 1998) and then according to the HKY85 $+\mathrm{I}+\mathrm{G}$ and GTR + I=G models, respectively. The Markov Chain Monte Carlo searches were run with 5 chains for $10,000,000$ generations with trees sampled every 500 generations (the first 20,000 trees were discarded as "burnin") and assessed using TRACER v1.4.1 (Rambaut and Drummond 2007). We used the program CAOS (Characteristic Attribute Organization System; Sarkar et al. 2008) to explore patterns of character distribution across the resulting phylogenetic hypothesis.

Finally, we used Network 4.5 (Fluxus) to construct a Median Joining network for an additional, expanded Dataset (III) of CR sequences ( $n=229$, Supplementary Table 2c) from an ongoing study of $R$. chiricahuensis. The structure of the resulting network was evaluated according to phylogenetic relationships recovered from analyses of the combined dataset.

\section{Results}

We successfully extracted DNA from 15 ethanol preserved, archival specimens of $R$. fisheri (Supplementary Table 1). We were unable to recover usable DNA from formalin 
a

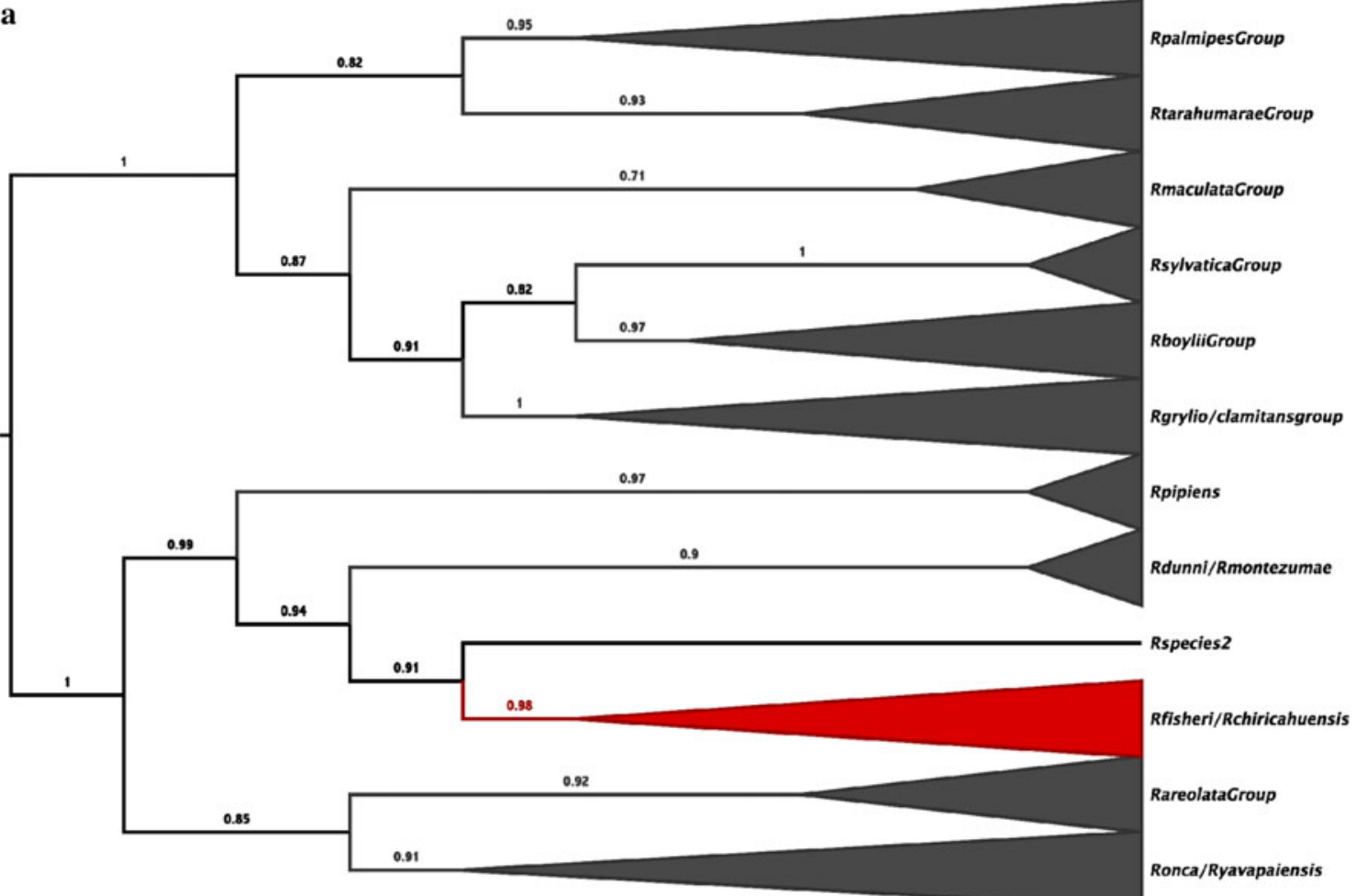

11

b

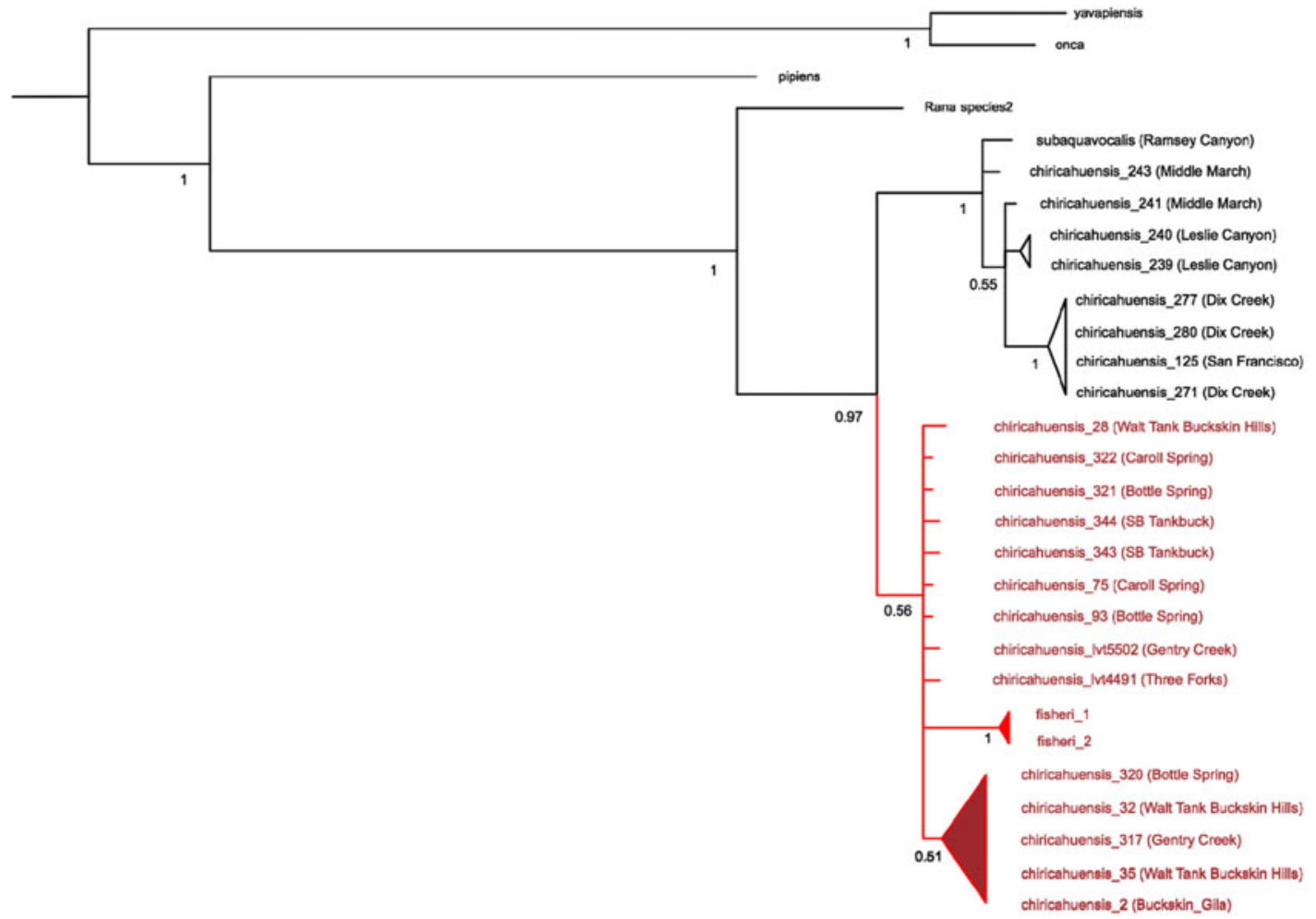

Fig. $150 \%$ majority rule consensus trees depicting results of Bayesian phylogenetic analysis of archival Rana fisheri based on a 12s mtDNA for published North American ranid frogs (Hillis and Wilcox 2005; Dataset I; Supplementary Table 2a) with red indicating focal species mentioned in the text; and b combined $12 \mathrm{~s}$, control region and rhodopsin exon 1 within $R$. chiricahuensis (Dataset II; Supplementary Table 2b). R. chiricahuensis individuals indicated in red are those from sites found closest to the Mogollon Rim 
preserved samples. The amplification success of individual specimens varied across gene regions. However, we were able to generate a minimum of 3 consistent sequences for each target gene region from between 5 and 15 individual specimens of $R$. fisheri (Table 1). As these sequences were invariant, we included 2 representative sequences in all subsequent analyses.

The broad comparison of $12 \mathrm{~s}$ mtDNA sequences from the entire collection of representative North American ranid frogs (Dataset I) placed $R$. fisheri within $R$. chiricahuensis, and as a distant relative of $R$. onca (Fig. 1a). Strong support was found for a sister relationship between the $R$. fisheri-R. chiricahuensis clade and "Rana Species2" from San Louis Potosi, Mexico (Hillis and Wilcox 2005). Additional support for this relationship came from alignment of the nuclear Rhodopsin exon 1 gene region, which indicated a 4 bp difference between $R$. fisheri and $R$. onca samples and no differences between $R$. fisheri and R. chiricahuensis.

Bayesian and ML phylogenetic analyses of the combined Dataset II using R. onca and Rana pipiens as outgroups revealed two clades: one consisting of $R$. fisheri plus $R$. chiricahuensis from the northwestern portion of its range near the Mogollon Rim, and another derived $R$. chiricahuensis clade including populations to the south and east (Fig. 1b). The CAOS analysis revealed the presence of 8 pure diagnostic and 6 private characters for the R. fisheri + northwestern chiricahuensis clade; and 7 pure diagnostic and 10 private characters for the southeastern clade including $R$. subaquavocalis (Table 2). Thus, mtDNA and nuclear sequences for the combined R. chiricahuensis Dataset II revealed the presence of fixed, diagnostic characters indicative of disrupted gene flow between two population aggregates (Davis and Nixon 1992).

Haplotype network analysis of the larger Control Region Dataset III recovered 17 haplotypes in two evolutionary lineages that correspond to the clades recovered in the analysis of the combined Dataset II (Fig. 2). The lineage that includes $R$. fisheri, which is differentiated from all other haplotypes by 7 substitutions, is distributed across the Mogollon Rim. Of the 55 localities included, only two harbor haplotypes from both CR lineages (Fig. 2).

\section{Discussion}

Genetic analysis of archival museum specimens has proven useful for determining the validity of taxonomic distinctions for imperiled and declining taxa (Bouzat et al. 1998; Goldstein and De Salle 2003). In this study, we examined archival specimens to resolve the taxonomy of $R$. fisherian extinct species-to advance recovery planning for leopard frog populations in southwestern North America. Phylogenetic analyses of nuclear and mtDNA sequence variation among century-old specimens placed $R$. fisheri within extant populations of $R$. chiricahuensis. Analyses of mtDNA variation indicate that specimens of $R$. fisheri in combination with $R$. chiricahuensis individuals from the northwestern portion of that species' range represent a diagnosably distinct lineage within $R$. chiricahuensis; a finding which is consistent with prior genetic analyses that distinguish between Mogollon Rim populations of $R$. chiricahuensis and populations in southern Arizona (Goldberg et al. 2004). According to nomenclatural priority, the northwestern lineage of $R$. chiricahuensis is referable to the previously described, extinct species, $R$. fisher $i$ Stejneger 1893.

The phylogenetic placement of $R$. fisheri from the Las Vegas Valley within northwestern Mogollon Rim populations of $R$. chiricahuensis (400 km distant) parallels biogeographic distributions of other species in the region (Lomolino et al. 1989). Within leopard frogs, for example, a divergent lineage of $R$. yavapaiensis occurs along the Colorado River in the western Grand Canyon (east of Las Vegas Valley), disjunct from other populations along the Mogollon Rim (Olah-Hemmings et al. 2010). The distribution and connectivity of habitats for vertebrate species in this region appear to have been greatly impacted by

Table 2 Results of CAOS analysis indicating diagnostic pure and private nucleotide character sites within aligned gene regions for $R$. fisheri $+N W R$. chiricahuensis and R. subaquavocalis $+S E R$. chiricahuensis clades

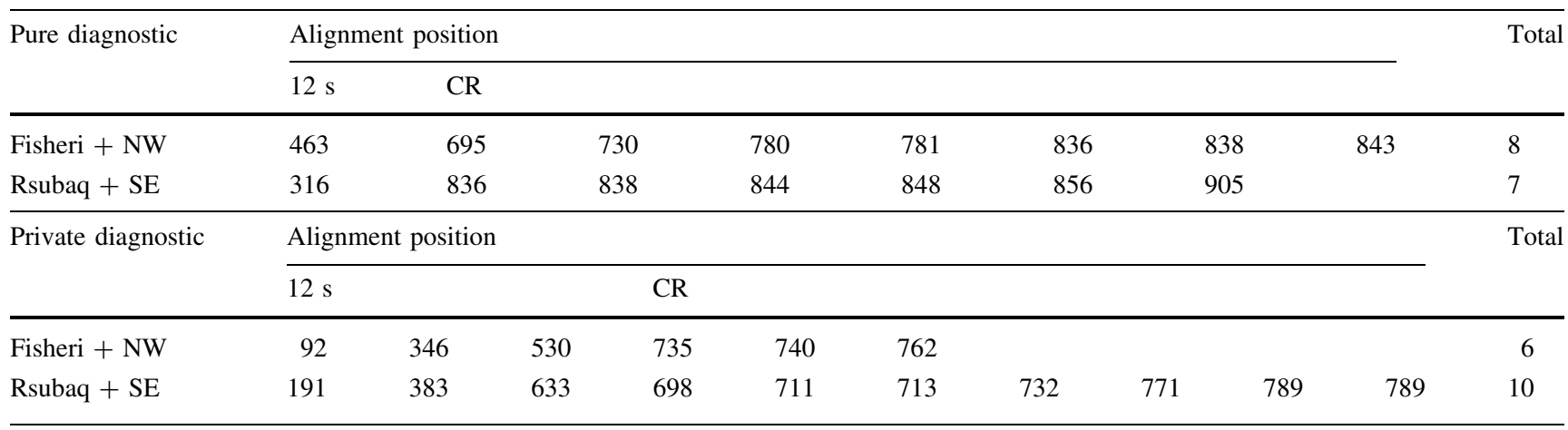




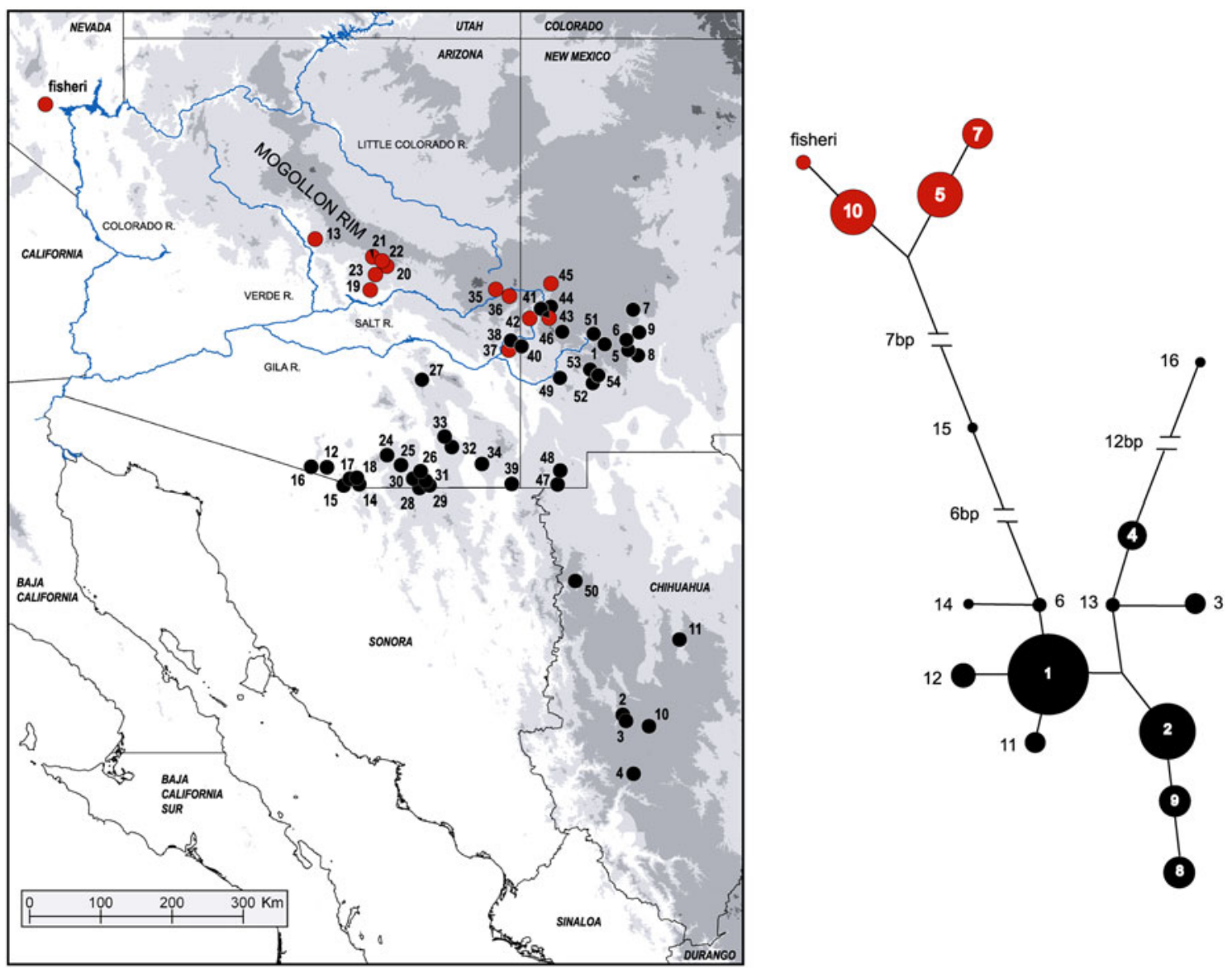

Fig. 2 Distribution of control region $R$. fisheri (red) and $R$. chiricahuensis (black) haplotype groups across 55 sample sites in the southwestern United States and Mexico, as presented in Supplementary Table 2c. Shading = elevation contours from lower

climatic change, possibly at scales less pronounced than those associated with glacial-interglacial cycles (Jaeger et al. 2005). Further phylogeographic studies and ecological niche modeling (e.g. Raxworthy et al. 2007), may provide valuable insight in resolving this pattern, and also help identify important areas of connectivity in the changing arid Southwest.

The unexpected resurrection of $R$. fisheri via phylogenetic placement of archival specimens highlights the utility of museum collections to provide evidence of pre-anthropogenic-disturbance conditions and better defines paths toward recovery of several imperiled leopard frogs in southwestern North America. Although the Chiricahua leopard frog may remain a valid taxon in southern (Goldberg et al. 2004) and eastern portions of its current range, clarification requires further analysis. Our data indicate that, at a minimum, northwestern populations of the species are now referable to $R$. fisheri. Accordingly, recovery plans, especially those that involve re-introductions into former habitat, should be reviewed in light of these findings. (white) to higher elevations (dark grey); black lines state boundaries; blue lines major rivers of geographical reference. (Inset) control region haplotype network for Dataset III with individual haplotypes as presented in Supplementary Table 2c, scaled according to frequency

Acknowledgments Thanks to J. Vindum at California Academy of Sciences for providing access to the historic specimens and M. Culver for access to recent specimens, E. Mujica for laboratory assistance, and Milind Bunyan for GIS support. Funding and logistical support were provided by the Las Vegas Valley Water District, the Blum Lab at Tulane University, Arizona Research Laboratories, and University of Arizona Genetics Core for DNA sequencing. We thank two anonymous reviewers for their helpful comments. The US Environmental Protection Agency, through its Office of Research and Development, collaborated in this research and has approved the article for publication.

Open Access This article is distributed under the terms of the Creative Commons Attribution Noncommercial License which permits any noncommercial use, distribution, and reproduction in any medium, provided the original author(s) and source are credited.

\section{References}

Bouzat JL, Lewin HA, Paige KN (1998) The ghost of genetic diversity past: historical DNA analysis of the Greater Prairie Chicken. Am Nat 152:1-6. doi:10.1086/286145 
Bradford DF, Jaeger JR, Jennings RD (2004) Population status and distribution of a decimated amphibian, the relict leopard frog (Rana onca). Southwestern Naturalist 49(2):218-228

Davis JI, Nixon KC (1992) Populations, genetic variation, and the delimitation of phylogenetic species. Syst Biol 41:421-435. doi: 10.1093/sysbio/41.4.421

Frost DR, Grant T, Faivovich J, Bain RH, Haas A, Haddad CFB, de Sá RO, Channing A, Wilkinson M, Donnellan SC, Raxworthy CJ, Campbell JA, Blottto BL, Moler P, Drewes RC, Nussbaum RA, Lynch JD, Green DM, Wheeler WC (2006) The amphibian tree of life. Bulletin of the American Museum of Natural History 297:1-370

Gilbert MTP, Bandelt H-J, Hofreiter M, Barnes I (2005) Assessing ancient DNA studies. Trends Ecol Evol 20:541-544

Goldberg CS, Field KJ, Sredl MJ (2004) Mitochondrial DNA sequences do not support species status of the Ramsey Canyon leopard frog (Rana subaquavocalis). J Herpetol 38:313-319. doi: 10.1670/117-03A

Goldstein PZ, De Salle R (2003) Calibrating phylogenetic species formation in a threatened insect using DNA from historical specimens. Mol Ecol 12:1993-1998. doi:10.1046/j.1365-294X. 2003.01860.x

Hillis DM, Wilcox TP (2005) Phylogeny of the New World true frogs (Rana). Mol Phylogenet Evol 34:299-314. doi:10.1016/j.ympev. 2004.10.007

Huelsenbeck JP, Ronquist F (2001) MRBAYES: Bayesian inference of phylogenetic trees. Bioinformatics 17:754-755

Jaeger JR, Riddle BR, Jennings RD, Bradford DF (2001) Rediscovering Rana onca: evidence for phylogenetically distinct leopard frogs from the border region of Nevada, Utah, and Arizona. Copeia 2001:339-354

Jaeger JR, Riddle BR, Bradford DF (2005) Cryptic Neogene vicariance and quaternary dispersal of the red-spotted toad (Bufo punctatus): insights on the evolution of North American warm desert biotas. Mol Ecol 14:3033-3048

Jennings MR (1988) Rana onca cope, relict leopard frog. Cat Am Amphib Reptiles 417:1-2

Jennings MR, Hayes MP (1994) Decline of native ranid frogs in the desert southwest. In: Brown PR, Wright JW (eds) Herpetology of the North American Deserts, proceedings of a symposium. Special Publication No. 5. Southwestern Herpetologists Society, Van Nuys, pp 183-211
Kleiman DG (1989) Reintroduction of captive animals for conservation. Bioscience 39:152-161

Larkin MA, Blackshields G, Brown NP, Chenna R, McGettigan PA et al (2007) Clustal W and Clustal X version 2.0. Bioinformatics 23:2947-2948

Lomolino MV, Brown JH, Davis R (1989) Island biogeography of montane forest mammals in the American Southwest. Ecology 70:180-194

Olah-Hemmings V, Jaeger JR, Sredl MJ, Schlaepfer MA, Jennings RD, Drost CA, Bradford DF, Riddle BR (2010) Phylogeography of declining relict and lowland leopard frogs in the desert southwest of North America. J Zool 280:343-354. doi: 10.1111/j.1469-7998.2009.00667.x

Platz JE, Mecham JS (1979) Rana chiricahuensis, a new species of leopard frog (Rana pipiens complex) from Arizona. Copeia 1979:383-390

Posada D, Crandall KA (1998) Modeltest: testing the model of DNA substitution. Bioinformatics 14:817-818

Rambaut A, Drummond AJ (2007) Tracer v1.4, Available from http://beast.bio.ed.ac.uk/Tracer

Raxworthy CJ, Ingram CM, Pearson RG (2007) Species delimitation applications for ecological niche modeling: a review and empirical evaluation using Phelsuma day gecko groups from Madagascar. Syst Biol 56:907-923

Sarkar IN, Planet PJ, De Salle R (2008) CAOS software for use in character based DNA barcoding. Mol Ecol Resour 8:1256-1259

Sredl MJ, Jennings RD (2005) Rana chiricahuensis Platz and Mecham, 1979; Chiricahua leopard frog. In: Lanoo MJ (ed) Amphibian declines; the conservation status of United States species. University of California Press, Berkeley, pp 546-549

Stebbins RC (1951) Amphibians of western North America. University of California Press, Berkeley

Tamura K, Dudley J, Nei M, Kumar S (2007) MEGA4: molecular evolutionary genetics analysis (MEGA) software version 4.0. Mol Biol Evol 24:1596-1599

Van Denburgh J, Slevin JR (1921) A list of the amphibians and reptiles of Nevada, with notes on the species in the collection of the Academy. Proc Calif Acad Sci 11(2):27-38

Wright AH, Wright AA (1949) Handbook of frogs and toads of the United States and Canada, 3rd edn. Comstock Publishing Co, Ithaca 